\title{
Über den isoelektrischen Punkt der tierischen Gewebe.
}

VI. Mitteilung.

Nochmals IEP der Erythrozyten einiger 'Tiere.

Von

\author{
G. Yasuzumi und S. Matsumoto. \\ Aus dem II. Anatomischen Institut der Medizinischen Fakultät der Kaiserlichen \\ Universität zu Osaka (Direktor: Prof. Dr. T. Tomita).
}

Mit 10 Textfiguren.

Auf Grund der Färbungstechnik, welche sowohl mit basischer als auch mit saurer Farbstofflösung variierter Wasserstoffionenkonzentration manipuliert wird, hat einer der Mitarbeiter, Yasuzumi, den IEP der Erythrozyten verschiedener Tierarten beobachtet und folgende phylogenetisch interessante Reihe bestimmt:

$$
\text { Avel }>\text { Reptilia }>\text { Amphibia }>\text { Fisch } \text {. }
$$

In Bezug auf den IEP des Kerns der Erythrozyten konnten wir die gleiche Tier-Reihe zeigen.

Hinsichtlich der Säugetiere liegt der Punkt in einem bestimmten sauren Bereich, d.h. pH $=6,78-6,39$. Dagegen hat M. Seki berichtet, dass die Erythrozyten von einer Membran umgeben sind, welche beim Trocknen zu dicht und zu engporig wird, also die fixierten Erythrozyten zunächst 1-2 Stunden in Wasser aufzubewahren und damn zu färben sind, und zufolge solcher Methode liegt der IEP der Erythrozyten der Säugetiere nach alkalischer Seite hin als $\mathrm{pH}=7,0$. Seine Ergebnisse wurden von Nishiin u ra bestätigt.

Ob der IEP der Erythozyten der Säugetiere nach alkalischer Seite oder saurer Seiter hin als $\mathrm{pH}=7,0$ liegt, wollen wir in dieser Untersuchung durch folgende beschriebene Methode nachprüfen. 


\section{Untersuchungsmethode und Resultate.}

Als Untersuchungsinaterial dienen die Erythrozyten von verschiedenen ausgewachsenen Tieren: Mensch, Kaninchen, Katze und Meerschweinchen.

1 ccm einer von Serum freien 10\%igen Blutlösung wurde 6 Stunden lang mit absolutem Alkohol fixiert und dam mehrmals mit Wasser ausgewaschen und weiter in $10 \mathrm{cmm} 0,01 \%$ iger Toluidinblau- od r $0,005 \%$ iger Ponceaulösung mit variierter Wasserstoffionenkonzentration (Farbstofflös. 9: Pufferlös. von McIlvaine 1) gefärbt. Nach 30 Minuten oder 3 Stunden wurde die Erythrozytensuspension zentrifugiert und der Farbstoffgehalt der Erythozyten nach der kolorimetrischen Methode mit , Rovibond-Tintometer" bestimmt. Zu diesem '/wecke wurden $1 \mathrm{ccm}$ des Zentrifugats im Laufe von 5 Minuten im siedenden Wasserbade mit $10 \mathrm{ccm} 2,5 \%$ iger Essigsäure und $1 \mathrm{ccm} \mathrm{H}_{2} \mathrm{O}_{2}$ (Perhydrol, Merck) erwärmt. Nach Abkühlung wurde die Lösung mit ,, Rovibond-Tintometer" bestimmt.

Wie schon I wanowsky und Sabolotnowa bemerkt haben, ist eine vorläufige Behandlung des Zentrifugats mit Essigsäure und Perhydrol vor dem Kolorimetrieren notwendig, da sich die Farbe des Methylenblaus in Anwesenheit der Erythrozyten etwas ins Schmutziggrüne verändert. Durch die erwähnte Bearbeitung verändert sich aber nicht die Nuance der Standardlösung.

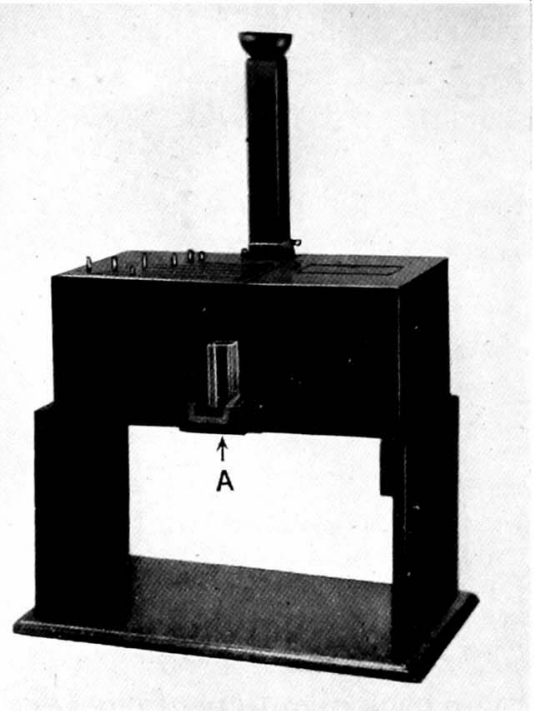

Fig. ].

Rovibond-Tintoncter

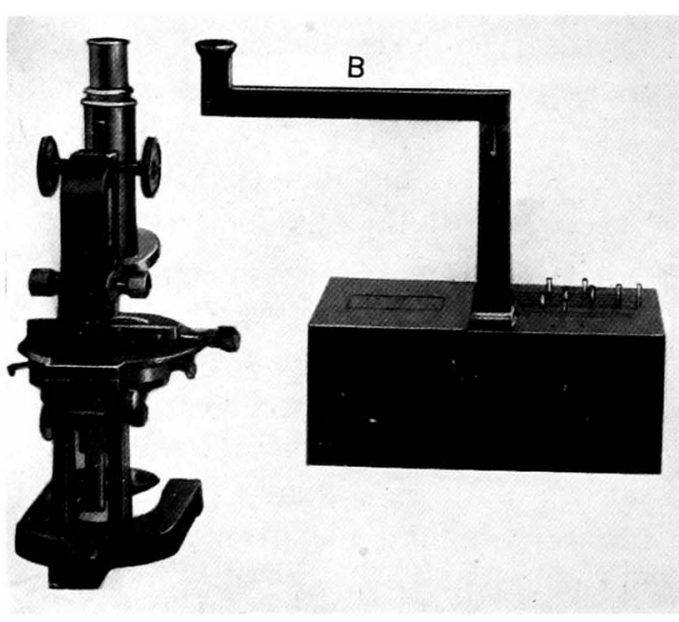

Fig. :.

Aplarat \%ur Bestimmung der Farbtïne der histologischen Prïparate. 
Zwecks genaueren Vergleichs des Färbtons haben wir ,, RovibondTintometer" angewandt, welcher aus 60 Standardgläsern besteht (Fig. 1). Eine Flasche A dient zum Vergleich des Farbtons der Farbstofflösung. 'Zur Bestimmung der Farbtöne der histologischen Präparate kommt ,,Rovibond-Tintometer" zur Anwendung, welcher mit dem von Yasuzumi hergestellten $\longrightarrow$ Rohr (B) mit zwei Planspiegeln an den Krümmungsstellen für Lichtbrechung versehen ist. Jieser Apparat ist in Fig. 2 zu sehen.

Man kommt zu folgenden Resultaten. Die Resultate sind in den nachstehenden Abbildungen dargestellt.

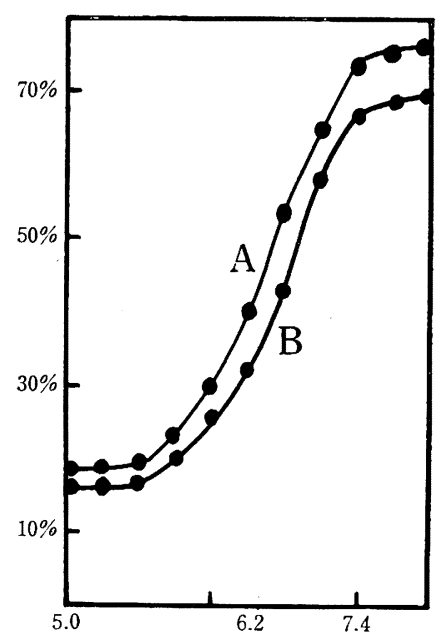

Fig. 3.

Kurven über die Färbung mit Toluidinblau der Kaninchen-Erythrozyten.

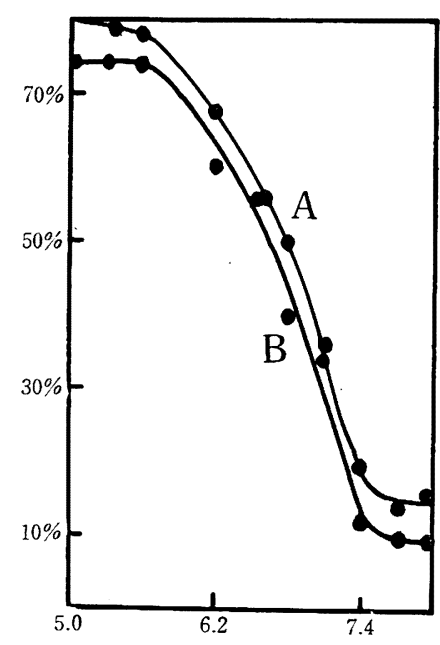

Fig. 4.

Kurven über die Färbung mit Ponceau der Kaninchen-Frythrozyten.

Auf der Abzisse wurden die pH-Werte abgetragen : auf der Ordinate der Farbstoffgehalt der Erythrozyten.

1: Die 3 Stunden lang gefärbten Resultate.

B: Die 30 Minuten lang gefärbten Resultate.

Die Kurve- A und B verlaufen fast parallel und beide zeigen in dem Bereiche $\mathrm{pH}=7,4-6,5$ die rasche Farbstoffadsorptionsabnahme; also liegt der IEP der Kaninchen-Erythrozyten wahrscheinlich in $\mathrm{pH}=6,5$, wie schon Yasuzumi gezeigt hat. Wie Nishimura und besonders Seki bemerkt haben, liegt der IEP nicht im alkalischen Bereiche. Bezüglich der Färbung der Strichpräparate müssen wir hier bemerken, dass das Strichpräparat schwer färbbar ist, wie Sek i gesagt hat, also eine längere Färbungszeit beansprucht. Jedoch ist es G. Yasuzumi gelungen, an dem mit Alkobol 

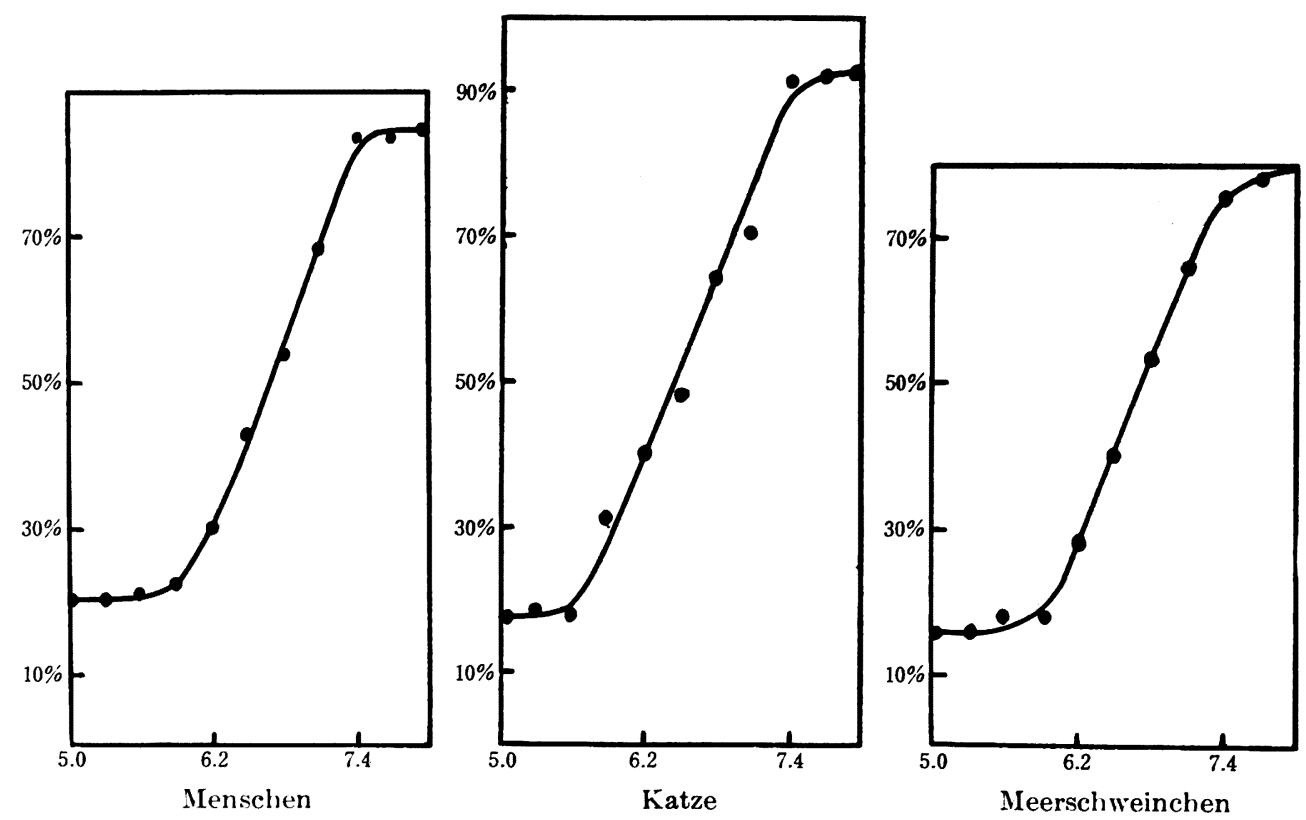

Fig. 5-7.

Kurven äber die Toluidinblau- Färbung der mit absolutem Alkohol fixierten Erythrozyten verschiedener Tierarten.
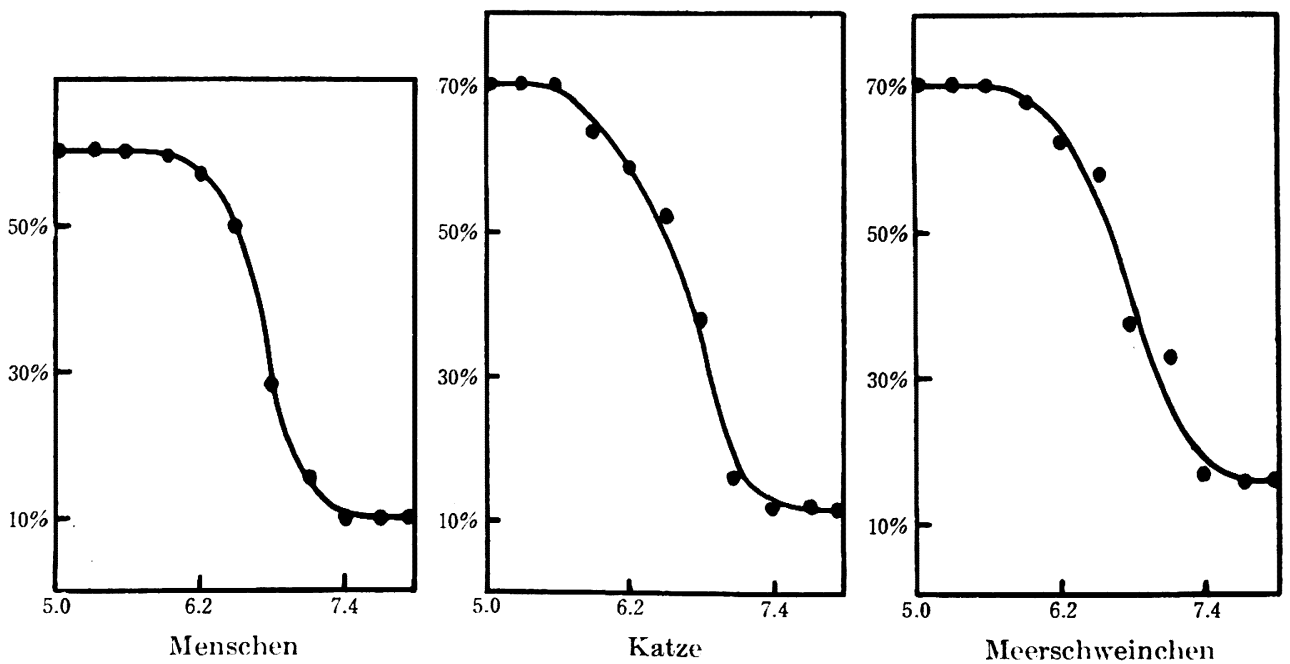

Fig. 8-10.

Kurven über die Ponceau-Färbung der mit absolutem Alkohol fixierten Erythro\%yten verschiedener Tierarten. 
fixierten und aufgeklebten Präparate das Plasma für 10 Minuten völlig zu färben. Die Verschiedenheit zwischen dem Ergebnis von Seki und der beiden Autoren gründet sich wahrscheinlich auf der Bestimmungsverschiedenheit der Färbungsintensität.

In oben beschriebenen Resultaten konnten wir keine Hemmungswirkung der Zellmembran für die Farbstoffdiffusion anmehmen. In den folgenden Untersuchungen wurden die Erythrozyten verschiedener Tierarten nur 30 Minuten lang gefärbt.

Wenn man die Ergebuisse zusammenfasst, so erhält man die folgende Tabelle.

Tabelle 1 .

IEP der mit absolutem Alkohol fixierten Erythrozyten verschiedener Tiere.

\begin{tabular}{|l|c|c|c|c|}
\hline & Menschen & Kaninchen & $\begin{array}{c}\text { Meerschwein- } \\
\text { chen }\end{array}$ & Katze \\
\hline Toluidinblau & $7,4-5,9(6,65)$ & $7,4-5,6(6,5)$ & $7,4-5,9(6,65)$ & $7,4-5,6(6,5)$ \\
\hline Ponceau & $7,4-6,1(6,75)$ & $7,4-5,6(6,5)$ & $7,7-5,9(6,7)$ & $7,4-5,6,6,5)$ \\
\hline IEP & 6,70 & 6,50 & 6,68 & 6,50 \\
\hline
\end{tabular}

Von unseren Beobachtungen stimmen die Resultate von Menschen, Kaninchen, Katze und Meerschweinchen fast mit den von einem der Mitarbeiter, G. Yasuzumi bestimmten Färbungsresultaten überein, während unsere Resultate mit den von M. Seki und T. Nishimura eine grosse Differenz zeigen.

\section{Zusammenfassung.}

In Bezug auf den IEP der Erythrozyten von Menschen, Kaninchen, Meerschweinchen und Katze konnten wir die von einem der Mitarbeiter G. Yasuzumi bestimmten Färbungsresultate nach einer anderen Methode bestätigen.

Zum Schlusse möchten wir Herrn Prof. Dr. T. Tomita für die Anregung zu dieser Arbeit unseren herzlichsten Dank aussprechen. 


\section{Literaturverzeichnis.}

1) Iwanowsky, N. u. Sabolotnowa, M., II. Adsorption von Methylenblau. Bioch. Zeitschr. Bd. 216. 1929.

2) Nishimura, T., Der isoelektrische Punkt der fixierten Hunde-, Menschen- und Kaninchenerythrozyten. Folia Anat. Jap. Bd. 12. 1934.

3) Seki, M., V. Bestimmung des isoelektrischen Punktes der fixierten Erythrozyten auf färbrischen Wege mit besonderer Berücksichtigung des Widerstandes der Zellmembran gegen Eindringen von Farbstoffen. Zeitschr. f. d. ges. exp. Medizin. Bd. 94.1934.

4) Yasuzumi, G., I. Bestimmungsmethode des isoelektrischen Punktes von Protoplasten und Verschiebung dieses Punktes der Erythrozyten von Kaninchen durch Formaldehyd. Folia Anat. Jap. Bd. 12. 1934.

5) Yasuzumi, G., II. Der isoelektrische Punkt der Erythrozyten verschiedener Tierarten. Folia A nat. Jap. Bd. 12.1934.

6) Yasuzumi, G. und Matsumoto, S., Ưber den isoelektrischen Punkt von Erythrozyten-Kern. Osaka Iji Shinshi. Bd. 6. 1935. 